\title{
O Recreador Mineiro (1845-1848): considerações sobre a transmissão de um discurso polifônico na imprensa mineira do século XIX
}

\author{
Luciano de Oliveira Fernandes
}

Resumo

Este estudo aborda aspectos polifônicos existentes no periódico literário $O$ Recreador Mineiro (Ouro Preto/ 1845-1848) indicando o uso da literatura, através do jornalismo, como um instrumento de apropriação social dos discursos com vistas à difusão da doutrina liberal na imprensa mineira do século XIX.

Palavras-chave: Jornalismo. Discurso. Polifonia. Romantismo. Recreador Mineiro.

"Os R R. , posto que na sua folha litteraria transmittão alguns artigos sem declarar a fonte de sua extracção, sustentão a ingenuidade de não roubar a anterior, ou phostuma gloria de pennas illustres. [...] cada um dos factos ali consignados não tem de certo por fonte peculiar, ou comum o cerebro do escriptor ; talvêz comprehenda a sua obra tantas linhas quantos os autores precedentes, ou contemporaneos donde as extrahio; [...] O R. Mineiro não é o catalogo, ou $\mathrm{O}$ atlas dos escriptores, cuja nomenclatura impreterivelmente deve apparecer nesse genero de producções; é pelo contrario o mensageiro do recreio, instruindo: e que mais conseguirá elle rubricando algumas paginas com a inscripção das fontes, em que se enriquecêra, que igualmente o não consiga sem taes rubricas? E é ponto bem singular, e genuino, que aquelles, que affirmão conhecer essas fontes, e que as designão por seus proprios nomes, sejão os mesmos que censurão o Recreador de as não declarar! Se vós as conheceis, para que solicitais declarações? Se julgais inutil a reproducção d'artigos, que tendes lido em diversas obras, apezar de que se não achem ao alcance de muitos outros, para que fim exigis contra vossos principios uma declaração do que vos é inutil por vos ser sabido?"

(os redatores do Recreador Mineiro, Escholio aos 6 volumes do Recreador Mineiro.)

Devo aqui confessar ao leitor que me fiz muitas perguntas após ler o fragmento acima. Questões de várias ordens que motivaram e impulsionaram a realização do estudo desenvolvido durante o mestrado ${ }^{1}$. Ao entrar em contato com o material que se 
constituiu como o corpus dessa pesquisa, a ausência de fontes e referências nos textos publicados por um jornal ouropretano do século XIX ${ }^{2}$ causou certo desconforto. Afinal, sempre se procura compreender os textos a partir de um ponto de enunciação inserido em um contexto discursivo; e em relação a uma série de outros documentos/monumentos (LE GOFF, 2003). Assim como a falta de referência aos autores da maioria dos textos publicados ao longo dos três anos da edição do periódico, deparar-se com as letras R.R. nos textos editoriais também causa certa dúvida. Afinal, quem são os "R.R", ou "Redatores do Recreador"? (nas edições aparece apenas o nome do editor: Bernardo Xavier Pinto de Souza) Para que finalidade "transmitem" o discurso alheio? Declaram não ter a intenção de se apropriar daquilo que transmitem; nem a de fazer do periódico um "atlas de escritores". Mas qual é então a intencionalidade dos R.R.? E como essa intencionalidade se articula com o poder e as forças sociais? Percebe-se no fragmento acima que as idéias de instrução e recreio perpassam a ideologia do jornal. São os objetivos dos redatores. E para tal, os R.R. não julgam serem úteis as rubricas, mas as idéias, o discurso contido naqueles textos. Mas que idéias? Que textos? Instruir para que finalidade? Quem? Mas em que situação ocorre essa transmissão do discurso de outrem?

Desculpe-me o leitor pela enxurrada de questões. Mas as questões se fazem necessárias como resposta àquilo que me foi argüido pelos R.R. As idéias contidas nos artigos do periódico se associam claramente à doutrina liberal; e podem ser reconhecidas enquanto tal, embora não sejam indicadas as fontes. Mas a pergunta tanto me inquietara: "Se vós as conheceis, para que solicitais declarações?" Para facilitar meu trabalho. Eis a resposta que daria a eles se pudesse voltar aos anos de 1845-1848 para solicitar informações que seriam inseridas na bibliografia deste estudo. Mas sendo isso humanamente impossível, como lidar com um aspecto, ou melhor, com a falta de um aspecto tão relevante para a realização das análises e constatação das hipóteses de um trabalho de pesquisa na área de Literatura Brasileira?

Pois bem, tempos depois a pergunta feita pelos redatores parecia ser a sua própria resposta. A "empresa literária", expressão pela qual costumavam os R.R. designar o Recreador Mineiro, constituía-se então como um suporte para a transmissão de um discurso polifônico - este, por sua vez, articular-se-ia com outros, numa perspectiva dialógica. Assim, a resposta ganhava forma de possibilidade de estudo. As questões acima pontuadas passaram mais a instigar do que a perturbar. Neste artigo observaremos, portanto, alguns elementos concernentes à análise do discurso e que podem melhor indicar como o discurso dos redatores de $O$ Recreador Mineiro se configurou como polifônico.

Em seu Esboço de uma Teoria polifônica da enunciação (DUCROT, 1987, p. 161218), Oswald Ducrot contesta e substitui o postulado da lingüística moderna de que cada enunciado possui um, e somente um autor: a unicidade do sujeito falante. Ducrot define a disciplina na qual se situam suas pesquisas chamando-a de Pragmática Semântica, ou Pragmática Lingüística. Termo este que designa as investigações que dizem respeito à ação humana realizada pela linguagem, indicando suas condições e seu alcance. Seu objeto é dar conta do que, segundo o enunciado, é feito pela fala. Segundo Ducrot, o enunciado se distingue rigorosamente da frase por poder ser tomado pelo lingüista como observável, considerado como uma manifestação particular. Em correlação com a oposição da frase e do enunciado, Ducrot introduz a diferença entre significação e sentido, falando da significação de uma frase para caracterizá-la semanticamente, e reservando o termo sentido para a caracterização semântica do enunciado. A concepção de sentido consiste em considerá-lo como uma 
descrição da enunciação. E uma vez que o autor considera que o enunciado pode ser compreendido como fragmento de discurso, considera também o discurso como um fenômeno observável, constituído de uma seqüência linear de enunciados. Ainda deve ser distinguida da frase e do enunciado a enunciação, termo ao qual Ducrot atribui três acepções, das quais toma a terceira como referência para seus estudos: 1) designar a atividade psico-fisiológica implicada pela produção do enunciado; 2) pode ser o produto da atividade do sujeito falante - o enunciado; e 3) o acontecimento constituído pelo aparecimento de um enunciado. A essa "aparição momentânea", Ducrot chama enunciação, sem fazer intervir em sua caracterização a noção de ato. Portanto, para Ducrot o sentido de um enunciado é a descrição de sua enunciação, que consiste (além dos aspectos argumentativos, ilocutórios e relativos às causas da fala) em indicações que o enunciado apresenta, no seu próprio sentido, sobre o (os) autor (es) eventual (is) da enunciação. Ducrot defende que é necessário distinguir, entre esses sujeitos, pelo menos dois tipos de personagens: os enunciadores e os locutores. O enunciador é aquele que é considerado como se expressando através da enunciação, sem que para tanto sejam a ele atribuídas palavras precisas; se ele fala é somente no sentido em que a enunciação é vista como expressando seu ponto de vista, sua posição, sua atitude, mas não no sentido material do termo, suas palavras. Ducrot fala em locutores (no plural) não para cobrir os casos em que o enunciado é referido a uma voz coletiva (por exemplo, quando um artigo tem dois autores, que se designam coletivamente por 'nós'); o que motiva o plural é a existência, para certos enunciados, de uma pluralidade de responsáveis. O locutor (ser discursivo) distingue-se do sujeito falante (ser empírico).

Na obra Marxismo e filosofia da linguagem (BAKHTIN, 1995), Mikhail Bakhtin considera que a língua é, como para Saussure, um fato social, cuja existência se funda na necessidade da comunicação, estando, assim, a fala "indissoluvelmente ligada às condições da comunicação e às estruturas sociais". Toda enunciação, por fazer parte de um processo de comunicação ininterrupto, é um elemento do diálogo - englobando as produções escritas. Desse modo, a enunciação é de natureza social, portanto ideológica, não existindo fora de um contexto social - já que cada locutor tem um 'horizonte social' e há sempre um interlocutor, ao menos potencial. Observando a "enunciação como realidade da língua e como estrutura sócio-ideológica", a palavra veicula de maneira privilegiada a ideologia e é um 'indicador' das mudanças. Bakhtin define a língua como "expressão das relações e lutas sociais, veiculando e sofrendo o efeito desta luta, servindo, ao mesmo tempo, de instrumento e de material." Desse modo, no capítulo, "Língua, fala e enunciação", Bakhtin considera que a palavra está sempre carregada de um "conteúdo ou sentido ideológico ou vivencial", e que reagimos somente àquelas que despertam em nós "ressonâncias ideológicas ou concernentes à vida." A língua, portanto, no seu uso prático, "é inseparável de seu conteúdo ideológico ou relativo à vida"; e a enunciação é o "produto da interação de dois indivíduos socialmente organizados." Portanto, o "centro organizador de toda enunciação, de toda expressão, não é interior, mas exterior: está situado no meio social que envolve o indivíduo." Assim Bakhtin define a enunciação como "realidade da linguagem e como estrutura sócio-ideológica." "A estrutura da enunciação é uma estrutura puramente social."

No capítulo "O 'discurso de outrem'", buscando ainda demonstrar a natureza social e não individual das variações estilísticas, Bakhtin considera que "a maneira de integrar 'o discurso de outrem' no contexto narrativo reflete as tendências sociais da interação verbal numa época e num grupo social dado." Faz-se conveniente, então, 
levar em conta que há diferenças essenciais entre a recepção ativa da enunciação de outrem e sua transmissão no interior de um contexto, uma vez que

toda transmissão, particularmente sob forma escrita, tem seu fim específico [...] Além disso, a transmissão leva em conta uma terceira pessoa - a pessoa a quem estão sendo transmitidas as enunciações citadas. Essa orientação para uma terceira pessoa é de primordial importância: ela reforça a influência das forças sociais organizadas sobre o modo de apreensão do discurso.

Toda a essência da apreensão apreciativa da enunciação de outrem, tudo o que pode ser ideologicamente significativo tem sua expressão no discurso interior. Aquele que apreende a enunciação de outrem não é um ser mudo, privado da palavra, mas ao contrário um ser cheio de palavras interiores.

O discurso citado e o contexto de transmissão são somente os termos de uma interrelação dinâmica. Essa dinâmica, por sua vez, reflete a dinâmica da inter-relação social dos indivíduos na comunicação ideológica verbal.

As condições da comunicação verbal, suas formas e seus métodos de diferenciação são determinados pelas condições sociais e econômicas da época. [...] nas formas pelas quais a língua registra as impressões do discurso de outrem e da personalidade do locutor, os tipos de comunicação sócio-ideológica em transformação no curso da história manifestamse com um relevo especial. (BAKHTIN, 1995, p. 146-148, 154)

Finalmente, como uma primeira resposta à questão proposta pelos redatores do Recreador Mineiro, nos aventuraremos a transmitir o discurso de Bakhtin, quando este nos declara que: "na verdade, dentro de uma situação em que todos os julgamentos sociais de valor são divididos em alternativas nítidas e distintas, não há lugar para uma atitude positiva e atenta a todos os componentes individualizantes da enunciação de outrem." (BAKHTIN, 1995, p. 149). Assim, observando a língua como um fato social ligado às estruturas sociais, à necessidade e às condições da comunicação, concluímos que os redatores do Recreador Mineiro procederam a uma enunciação polifônica (DUCROT, 1987), caracterizam-se como locutores (transmissores de um discurso dotado de uma pluralidade de responsáveis) e, portanto, expressam conformidade com as idéias e o ponto de vista de vários enunciadores (sem que para tanto sejam a eles atribuídas palavras precisas ou rubricas que os declarem como fonte) através de uma seleção do que seria apropriado ou descartado pelo discurso a ser transmitido. Verificamos, portanto, que o "centro organizador" da enunciação polifônica em $O$ Recreador Mineiro era exterior, situava-se no meio social que envolvia os redatoreslocutores, o discurso a ser transmitido, e o público para o qual ocorreu a transmissão. Desse modo, no que diz respeito ao processo de comunicação, evidencia-se o postulado de que a estrutura da enunciação é de natureza puramente social e ideológica. Assim, a enunciação polifônica se manifestou em O Recreador Mineiro como um "indicador" das mudanças, como "expressão das relações e lutas sociais, veiculando e sofrendo o efeito desta luta, servindo, ao mesmo tempo, de instrumento e de material" (BAKHTIN, 1995).

Levando em conta as diferenças essenciais entre a recepção ativa da enunciação de outrem e sua transmissão no interior do contexto romântico de renovação política e cultural, concluímos que a maneira de se apropriar do 'discurso de outrem' evidenciou em $O$ Recreador Mineiro as tendências sociais da interação verbal em Minas Gerais na primeira metade do século XIX, uma vez que a existência de um público leitor evidencia o fluxo das forças sociais organizadas sobre o modo de apreensão do discurso de outrem no referido periódico. Isto que aponta para a interação dinâmica entre o discurso citado e o contexto de transmissão, evidenciando: a inter-relação social dos indivíduos na comunicação ideológica verbal; a atuação da facção política 
liberal em Minas após a Independência através da imprensa; e o uso da Literatura como instrumento e material de um processo de renovação política, ideológica e cultural em Minas Gerais no período romântico.

Ao se referir à "apropriação social dos discursos" (FOUCAULT, 2004), Michel Foucault considera ainda que todo sistema de educação como "é uma maneira política de manter ou modificar a apropriação dos discursos, com os saberes e poderes que eles trazem consigo" com a finalidade de constituir "um grupo doutrinário ao menos difuso" através de "uma distribuição e uma apropriação do discurso". Deve-se, nesse ponto, observar que a epígrafe dada a este artigo permite que verifiquemos a declaração da função pedagógica e doutrinária do periódico, caracterizada por seus próprios redatores.

Assim, a apropriação social dos discursos operou-se para a difusão da doutrina liberal em $O$ Recreador Mineiro. A polifonia se fez presente em $O$ Recreador Mineiro através do efeito que resulta do conjunto harmônico de instrumentos e linguagens do romantismo, bem como através da pluralidade de diversas vozes que soaram simultaneamente para a transmissão da doutrina liberal através do discurso dos redatores do referido periódico.

Abstract

This paper approaches polyphonic aspects existent in the literary periodical O Recreador Mineiro (Ouro Preto/ 1845-1848) and displays the use of literature, through journalism, as an instrument of social appropriation of the discourses to transmit and diffuse the liberal doctrine in the press from the $19^{\text {th }}$ century in Minas Gerais.

Key words: Journalism. Discourse. Polyphony. Romanticism. Recreador Mineiro. 


\title{
Referências
}

BAKHTIN, Mikhail. Marxismo e filosofia da linguagem. Tradução de Michel Lahaud e lara Frateschi Vieira. São Paulo: Hucitec, 1995.

DUCROT, Oswald. Esboço de uma Teoria Polifônica da

Enunciação. In: O Dizer e o Dito. Revisão técnica da tradução: Eduardo Guimarães. Campinas, SP: Pontes, 1987. p. 161-218.

FOUCAULT. Michel. A ordem do Discurso. Tradução de Laura Fraga de Almeida Sampaio. 10. ed. São Paulo: Edições Loyola, 2004.

LE GOFF, Jacques. História e memória. 5.ed. Campinas, SP: Editora da UNICAMP, 2003.

O RECREADOR MINEIRO. Ouro Preto: Typographia Imparcial de Bernardo Xavier Pinto de Souza: 1845 - 1848. Tomos I a VII (Biblioteca Nacional)

\begin{abstract}
1
${ }^{1}$ Discutindo as articulações entre experiência vivida, ficção e organização social através do estabelecimento de relações entre história, memória cultural e literatura, o referido estudo (intitulado O Recreador Mineiro (1845-1848): liberalismo e romance-folhetim na imprensa mineira do século XIX) visa a analisar a relação entre a imprensa mineira e a facção política liberal em Minas Gerais após a Independência, bem como os efeitos dessa relação na temática dos artigos e dos folhetins publicados no periódico ouropretano $O$ Recreador Mineiro (1845-1848). Constatando que esse periódico se caracterizou como um suporte para a enunciação de um discurso polifônico, procura-se também analisar o uso da Literatura (através do jornalismo) como instrumento do processo de renovação política, ideológica e cultural em Minas Gerais no período compreendido entre 1845 e 1848.

${ }_{2}^{2}$ Publicados quinzenalmente entre $1^{\circ}$ de janeiro de 1845 e 15 de junho de 1848 pela "Tipographia Imparcial de Bernardo Xavier Pinto de Souza", os 84 números de 0 Recreador Mineiro foram divididos em sete tomos por Bernardo Xavier, responsável pela fundação, direção e edição desse periódico. Em consonância com a vastidão de campos intelectuais abarcados pela proposta romântica, cada tomo do Recreador foi dividido em três seções. Na primeira delas, intitulada "Memória", é abordada a "História". Na segunda seção, intitulada "Razão", é abordada a "Philosophia". Por sua vez, a terceira seção, dedicada à "Imaginação", contém cantigas e poesia nos gêneros épico e lírico.
\end{abstract}

